\title{
Major Successes and Challenges of African Peace and Security Architecture (APSA)
}

\author{
Yayew Genet Chekol* \\ Lecturer, Department of civics and ethical studies, college of social science and humanities, Salale University, \\ Fiche, Ethiopia
}

*Corresponding Author: Yayew Genet Chekol, Lecturer, Department of civics and ethical studies, college of social science and humanities, Salale University, Fiche, Ethiopia

\begin{abstract}
The African continent has been found in conflicts and insecurity for the last years. Attempts have been made to prevent and resolve some of these conflicts and the continent meet some achievements in the area particularly when AU formulated the concept of the African Peace and Security Architecture (APSA), which is considered as a new promising African security initiative. However, the APSA is challenging some hindrances. The article is therefore centered on the achievements and challenges the APSA. The continent leaders have come to the realization that unless Africa puts in place the appropriate effective measures and mechanisms to prevent, manage and resolve conflicts more seriously than ever before, Africa would continue to bear the disastrous effects of conflicts.
\end{abstract}

\section{INTRODUCTION}

The African Peace and Security Architecture (APSA) refer to the collective pillars that constitute the AU's peace and security framework outlined in its 2000 Constitutive Act and the 2002 Peace and Security Protocol. These include the Peace and Security Council (PSC), the Panel of the Wise (PoW), the African Standby Force (ASF), the Continental Early Warning System (CEWS), and the AU Peace Fund. The APSA is at the center of the AU's peace and conflict agenda, which includes conflict prevention, early warning and preventive diplomacy, peacemaking and peace building, the encouragement and promotion of democratic practices and intervention, and humanitarian action and disaster management (Fahle, 2015).

The APSA emerged from the desire of African leaders to establish an operational structure to execute decisions based on the authority conferred by Article 5 (2) of the AU's Constitutive Act. The effective operationalization of the APSA requires the setting up of functional systems at the sub-regional level through Regional Economic Communities (RECs) and Regional Mechanisms (RMs). As a follow-up, a Memorandum of Understanding between the AU and the RECs/RMs was signed in January 2008, and the RECs/RMs now has official representation through the AU to facilitate coordination and collaboration (AU, 2016a).As a result, it can be argued that the APSA provides the AU and the RECs/RMs with the necessary support to undertake their roles of prevention, management, and resolution of conflict on the continent. In general, the adoption of a continental peace and security architecture has been viewed positively in terms of preventive diplomacy, mediation, and peace support operations (AU, 2016a).

However, an AU-commissioned assessment report on the APSA has called for greater flexibility for the incorporation of methods to address emerging political and security issues such as election-related violence, piracy, and terrorism, as well as the incorporation of security sector reforms and transitional justice, within its pillars (Williams and Hashi, 2016).

\section{THE INSTITUTIONAL FRAMEWORK OF THE APSA}

With the establishment of the AU and the APSA, a number of bodies were established which function as the institutional skeleton of the AU's and REC's day to day interventions and activities in peace and security in Africa. The APSA is institutionally diverse and far from static. The APSA and its institutions, while building on experiences selected RECs and similar structures in the RECs, function 
as a platform for cooperation and coordination within the APSA, with similar bodies at the REC level, as well as with external partners. It is composed of the following elements:

The Peace and Security Council (PSC) is the AU's standing decision-making organ for the prevention, management and resolution of conflicts (PSC Protocol, Art. 2(1)) body and the cornerstone of the APSA. The PSC is made up of 15 members, 10 of which are elected for a term of two years, while five are elected to serve for three years. The PSC is designed to provide "a collective security and early-warning arrangement to facilitate timely and efficient response to conflict and crisis situations in Africa (Bah et all, 2014)"

The African Union Commission is responsible for the implementation of PSC decisions and provides operational support. This happens mainly through the AU Commission Chairperson and the AU Commissioner for Peace and Security, who report to the PSC on the implementation of PSC decisions and their own initiatives. The Chairperson and Commissioner are supported by the Peace and Security Department (PSD).

The African Standby Force (ASF) is the multi-dimensional force of the APSA covering police, military and civilian dimensions. It was established by Article 13 of the PSC Protocol (Bah et all, 2014), and is made up of five regional and multidisciplinary brigades. The ASF includes military, civilian and police elements, which are expected to complement each other when mandated to implement PSC decisions that have to do with Peace Support Operations (PSO).

The Panel of the Wise (PoW) is an advisory component of the APSA with 'silent' and preventive diplomacy as its main areas of engagement. It consists of five prominent African personalities (Desmidt, 2016). Each member represents one of the five regions of the continent. Members of the Panel act to promote peace and resolve conflicts either on the invitation of the PSC, the Chairperson of the Commission or on their own initiative (Bah et all, 2014). The Panel of the Wise has been engaged in different conflict contexts since its inauguration in 2007, including Madagascar, Egypt and Kenya.

The Peace Fund is a financial instrument created under Article 21 of the PSC protocol. The PF shall provide the necessary financial resources for the operationalization of the APSA. The Peace Fund is supposed to be funded through contributions from donors, member states, private sector, civil society and individuals.

The Continental Early Warning System (CEWS) is the AU's early warning system and aims to provide timely and reliable data to warn the PSC and the AU Commission of potential conflicts and outbreaks of violence. The CEWS coordinates efforts where possible with similar structures in the RECs.

\section{OVER VIEW OF African Threats to PeaCe AND SECURITY}

The internal and external political, economic and social determinants, causes, triggers and accelerators of peace and security in the African continent will continue to be(Lotze,2013):(a)Socio-economic stressors: in the form of extreme poverty and low human development, income inequality and exclusion in developmental dividend; (b) Demographic stressors in the form of youth unemployment and population bulge, and the mismatch with service delivery;(c) Climate change and environmental stressors: in the form of droughts and flooding that severely affect large parts of the region particularly formerly neglected areas;(d) Deficit in governance: undemocratic and irresponsive nature of states, undemocratic platforms of mobilization of social and political forces, limited accommodation of diversity of identity markers such as religion and ethnicity, corruption and lack of accountability, election-related disputes and violence;(e) Border Disputes and Weak Cross Border Governance: manifested in nation building based on animosity to neighboring countries, border disputes and conflicts, and low infrastructural development and weak cross border governance will exacerbate the security challenges;(f) Transnational threats and organized criminal activities: in the form of terrorism and violent extremism, human and drug trafficking, smuggling of persons, unsafe route migrations; (g)Unwarranted external interference and spillover effects of unstable neighborhood: The African continent is in the same trade, religious, migration and security zone with the immediate Middle East and European countries, the on-going crises in Yemen, and Libya directly affect the region.. Facing the dichotomy of crises and transformations, transitions are characterized by unpredictability and volatility. Only correct interventions that support the transformation process 
ensure that crises are abated and gradually reduced and eliminated from the continent. In peace and security, transformation requires in building the predictive, preventive, responsive and adaptive capabilities of the APSA (Gelot, et all, 2012)

These capabilities are a function of resistance to vulnerabilities of internal and external factors and shocks, which would also most often be a function of socio-economic development and governance. Thus, for the continent to be more stable, transformation needs to outpace crisis. Crucially, governance responsiveness will determine this pace, and in turn governance will determine the peace and security of the area. States are the central actors in the transformation of the continent without which peace and security, governance, development and stability cannot be achieved. The requisite capabilities to predict, prevent, respond and adapt to these vulnerabilities and threats are yet to be fully built in the APSA and its subsidiaries in the continent (deConing and et all, 2016) Hence, the people of the Africa expect robust participation, political will and determination from the leadership of the AU Member States in the implementation of this Strategy. While governance deficit is one of the cause and accelerator of the challenges to peace and security in the continent, at the same time, governance is the game changer in determining the peace and security situation in the continent (Wallensteen, nd).Thus, for the continent to be more stable, transformation needs to outpace the impacts of these stressors and the crises afflicting the continent. It has faced and continues to face myriads of peace and security threats. But the APSA is also presented with opportunities if seized timely could help address most of the threats. The Strategy will compliment other sectors and in building Member States' capabilities in four areas of prediction, prevention, response and adaption in order address current trends of exclusive development into inclusive one, turn demographic growth from liability to asset, build climate resilience communities, and increase legal mobility and reduce displacement and unsafe route migrations and curb unwarranted interferences and negative implications of the crises in the Middle East and Western powers .the focal point of this paper is to discuss the major achievements and challenges of African peace and security arctecture. The paper has been written by using the documentary source of data, specifically the recent UN reports are employed in this paper.

\section{SuCCESSES AND Challenges OF APSA}

\subsection{Successes}

With continued AU engagement with Member States on conflict prevention, management, resolution and post conflict reconstruction and development as well as peace-building initiatives, progress is being made in the signing and implementation of peace agreements between countries not at peace, or those emerging from decades of conflict and instability ( Fahle, 2015). The human and economic costs of these conflicts had adverse national and cross-border consequences: Increased numbers of refugees and internally displaced persons; the proliferation of small arms and light weapons, and many more.

In response, and in line with the provisions of the Constitutive Act of the African Union and the Protocol Relating to the Establishment of the Peace and Security Council (PSC Protocol), the AU assumed political responsibility to address these challenges and developed its African Peace and Security Architecture (APSA). Over the last decade, the extent of violent conflict on the continent has reduced, despite the emergence of new security threats (AU, 2016b).

The Commission has recently published the APSA Roadmap 2016 -2020, a strategic document, which builds on the achievements and challenges resulting from the implementation of the previous APSA Roadmaps (2011-2013). The Roadmap manifests the continued determination to ensure further progress, and paves the way for future collaboration between the AU, the Regional Economic Communities (RECs) and Regional Mechanisms (RMs) to effectively address security issues and contribute to a more peaceful Africa.

Even though the key components of APSA are now more or less fully operational and the number of violent conflicts has been significantly reduced in the past few years, a number of countries still remain trapped in a vicious cycle of violent conflict and its deadly consequences. With a view to realizing the goal of a conflict-free Africa, the discussion during the Summit will focus on conflict and crisis situations in Africa namely, Democratic Republic of Congo, Central African Republic, Somalia, Sahel/Mali, South Sudan, Burundi, Guinea Bissau, Libya among others. A continued strong engagement in support of implementation of peace agreements in Member States emerging from 
conflict and the fight against terrorism will remain the priorities for the AU (Loteze, 2013). Somalia could be sighted as an example that has made significant progress against Al -Shabaab with support from the African Union Mission in Somalia (AMISOM).On its part, AMISOM continues to provide guidance on capacity building, and sensitization of communities on countering violent extremism, as part of its comprehensive strategy for reviving policing activities in Somalia (William and Hashi, 2016).

In the context of conflict prevention, the AU and its sub-regional organizations have developed significant institutional capacity over the past decade to undertake early warning analysis and conflict prevention. In this regard, the AU has built up an impressive toolbox for prevention and peacemaking. These include the Continental Early Warning System, the Panel of the Wise, Special Envoys, and ad hoc mediation panels, often comprised of sitting and former Heads of State. The AU also has experience in deploying liaison offices and "special political missions" in countries at risk of, or emerging from, conflict (AU, 2016a). The Commission has focused on operational conflict prevention with regular Horizon Scanning briefings provided to the AUPSC on potential threats and emerging peace and security challenges on the continent; production of early warning reports and the conduct of preventive diplomacy missions in Member States at risk of conflict. The Commission has also continued to provide technical assistance to Member States in the establishment and strengthening of national infrastructures for peace, including early warning systems and Situation Rooms (AU, 2016a).

In the context of post-conflict reconstruction and support of countries, the Commission deploys mission to assess the priority needs of the country in need. These include identification of joint activities in support of implementation of peace agreements in Member States emerging from conflict; conducting needs assessment missions; consolidating and scaling up security sector reform and disarmament, demobilization and reintegration initiatives; technical and operational support to control the illicit proliferation of small arms and light weapons, and sustained collaboration with RECs/RMs and civil society organizations (Walensteen,nd). The engagements have also been geared towards developing and implementing Quick Impact Projects (QIPs) and Peace Strengthening Projects (PSPs) in areas of deployment of AU Peace Support Operations, and through the AU Liaison Offices. Furthermore, the AU took a number of initiatives to prevent the post-electoral situation from degenerating into a generalized crisis through the deployment of observers.

The AU Commission also provides strategic, political, technical, and planning support to operations authorized by the Peace and Security Council and carried out by regional coalitions of Member States, Regional Economic Communities (RECs), or Regional Mechanisms for Conflict Prevention, Management and Resolution (RMs) deConing and et all,2016). Such support includes: The Regional Cooperation Initiative against the Lord's Resistance Army (RCI-LRA) and the operation against Boko Haram undertaken by the Lake Chad Basin Commission and Benin-the Multinational Joint Task Force (MNJTF)(Musah,2011).

It is important to highlight the critical nature of the partnerships the AU has developed within the framework of APSA. The European Union (EU), United Nations (UN) and bilateral partners have all played a key role. There has been significant innovation and creative problem solving, which has been pivotal in meeting the continent's peace and security challenges

\subsection{Challenges Confronting the African Peace and Security Architecture}

The African continent continued to grapple with a range of transnational security threats, including the ramifications of global security developments. Terrorism has taken on greater proportions and expanded geographically, with the 2017 year being marked by some of the deadliest terrorist attacks ever witnessed on the continent. In response, actions were taken, through the Commission and specific regional security arrangements, to degrade the capability of terrorist and criminal groups in Somalia, the Lake Chad Basin and in the Sahel region (AU, 2017).

The AU's notion of retreat remains premised on human security. Awkwardly, the peace, security council (PSC) allots further consideration to martial or military features of security in the outlay of further intimidations to security in Africa such as diseases, environmental degradation, drug trafficking and piracy, to mention but a few. The PSC necessities to widen its mandate and activities to include these seemingly non-conventional threats to peace and security in Africa (Williams, 2009). This will increase peace, security, development and stability in Africa. Moreover, the PSC lacks the indispensable human and financial resources to fulfill its mandate. The AU is generally cash strapped 
and that has a consequential adverse effect on the PSC. Also, most African states would hardly send their talented and experience top level diplomats or bureaucrats to the PSC in particular and the AU in general (Ibid). As a result, the PSC is under the weather engaged to accomplish efficiently and effectively. Hence, African governments need to be more enthusiastic to the root of the AU.

According to Williams (2009) there is another challenge threatening the APSA is the implementation of the CEWS. However, a number of workshops have been held in that regard, a lot still remains to be done. The AU, ECOWAS and IGAD early warning systems are the only systems to have made significant progress. However, like the other RECs' early warning systems, they lack adequate staffing and funding to cover their vast regions and the numerous issues to be reported on under human security (Debial, 2009).

Franke (2005) in his work stated that they also lack the aptitude to efficiently analyze the data collected. So their capabilities as effective early warning systems are yet to be comprehended. For example, the critics of the CEWS are of the interpretation that there is adequate evidence of indicators of state failure and the likelihood of conflict in countries such as Guinea, Guinea-Bissau, Equatorial Guinea and Zimbabwe, but there is clear lack of early and well unified preventive efforts by regional mechanisms (Malan, 2012).

The PoW's order is further around preventing conflicts rather than managing conflicts. Nonetheless, it lacks pleasing human and financial means to accomplish its purposes (Laurine, 2005). Presently, it needs adequate provision staff with expertise in mediation and technically competent professionals on detailed conflict regions. This is pertinent for the PoW's imperfect membership of five could limit its aptitude to applicably respond to prospective hostile circumstances that necessitate its devotion. The aforementioned also permits for steadiness while the panel members are changed at the culmination of their tour of duty (Jamila, 2012).

The ASF is the vital apparatus that the AU anticipates to custom to execute its peace and security agenda. Though the institutional framework and doctrines for the ASF have been completed, the authentic executing structures are still not completely advanced as a result of the unhurried pace of progress. So far, ECOBRIG, EASBRIG and SADCBRIG have made substantial advancement. Hence, the ASF could not be fully operational by 2010 as planned (Egnell and Lgerstorm, 2012). A number of factors accounts for this slow pace of work.

The provincial tools and the AU in its completeness are money needy and resource starved. Merely a limited of the AU member states are up to hurry with their costs to the AU regular budget. South Africa, Nigeria, Egypt, Algeria and Libya pay fifteen percent each of the AU regular budgets, totaling seventy-five percent (William, 2009). Though African Heads of State endorsed the three year strategic plan of Alphar Konare (first Chairman of AU Commission) aimed at enhancing the AU structures to curtail security threats in Africa, they only paid lip service to the plan. The plan included a proposed $\$ 600$ million annual implementation budget but the Heads of States failed to commit themselves to this proposal.

African governments hardly see international cooperation as a policy priority especially when it comes to making financial commitments despite the enormous resources some of them has (Malan, 2005). That notwithstanding, it is noteworthy to reference that Africa is overwhelmed in a total debt of about $\$ 305$ billion, it accounts for hardly one percent of foreign direct investment, one percent of global gross domestic product and below two percent of international trade. Africa receives about $\$ 22$ billion a year in foreign aid and it would cost the continent approximately $\$ 64$ billion per year to implement its economic strategic plan, the New Partnership for Africa's Development (NEPAD)(Ibid). It is correspondingly imperative to indicate that AU member states are among the poorest in the world and their despondent national budgets are in furthermost circumstances mainly financed by international donors (Egnell and Legerstorm, 2011).

Hence, the AU cannot stand its peace and security agenda in devoid of the funding donor of associates and the international community. For example, without the EU African Peace Support Facility (APSF), the AU would not be in a place to comportment peace backing processes (Murithi and Angela, 2005). Similarly, the AU and the RECs have not yet proven logistics depots to support peace support operations (PSOs).

Another disturbing condition which challenges the APSA is the institutional disorder on the continent 
someplace utmost African states have its place to two or more of the web of fourteen intergovernmental organizations in Africa which pursue to deliver some form of security and conflict management mechanisms. Out of the 54 AU member states (one state no member of AU), 26 belong to two regional groups whilst 19 belong to three. Even DRC and Swaziland are members of four regional communities. Which intersecting memberships incline to unpleasantly upset the shared objective ,in addition to the combination goals of the AU as a result of counterproductive antagonism and replication of efforts. Hence specific member states culminate in disintegrating their financial, human and material resources and are incapable to provide to the AU's peace and security effort (Franke, 2005). Therefore, AU member states must drill their main concern and free from some of the regional organizations.

The nature and worth of funding from Africa's development partners decreased and undersized of the desired capability constructing programs are obligatory to heighten the APSA. Western and external actors have often used their financial power to contour and impact the limits of security in Africa contrary to what Africans might perceive as an African answer to an African problem. For instance, the notion of launching an AU Counter-Terrorism Center is static being questioned. Correspondingly, international partners center more on peacekeeping training for AU member states comparative to the delivery of logistics sustenance such as strategic airlift, communication equipment and armored vehicles. Furthermore, there is no synchronization and coordination of the various donor supports to the AU. Lastly, donor support is geared towards immediate and short-term crisis at the expense of long-term capacity building programs such as the ASF and the CEWS (Franke, 2005)

One of the major challenges faced by the APSA institutions is to strengthen their capacity to a level equal to their political ambitions. Financial ex-post audits are systematically conducted for all APF interventions, including AU-led PSOs. Several of these audits have identified weaknesses related to the financial management and internal control of the African partner implementing organization, which has led the European Commission to considerably increase its focus on this area. The European Commission and the AUC signed an Aide Memoire in April 2016 to strengthen the AUC's financial management capacities. Such measures also apply to the RECs/RMs whose audits revealed critical financial findings (European commission Report, 2013).

The APSA's absence of capability to resolve crisis was verified once it failed to intervene in Somalia after Ethiopia invaded Somalia in December 2006. Eventually, when the AU decided to send a force of 8,000 to Somalia as the African Union Mission in Somalia (AMISOM), only Uganda provided 1,200 troops for the mission in March 2007(Egnell and Legerstorm, 2011). Here there were also delays in the placement of the force. It took months to set up the force command center and the Support Management and Planning Unit. The force lacked sufficient financial and physical capitals.

However some of AU's development partners vowed considerable financial funding, the initiates were far less than the $\$ 622$ million required for the original launching of the force (Franke, 2005). The African Union Mission in Sudan (AMIS) had similar challenges. There was no passable preparation prior to the deployment of the force. Also, it lacked the suitable configurations for deliberately and operative command and regulate as well as logistics patronage. The mission be contingent merely on aid from international donors and hence there was causing in delays, uncertainty and misunderstanding (Bogland, 2011).

The major challenge facing the African Union is the lack of funds. The financing challenge the AU is faced with has important unintended consequences. High levels of donor dependency have weakened ownership in this critical area of the AU's mandate and led to strategic drift, as the AU Commission increasingly focused on externally financed activities. There is general agreement that the current financing arrangements for peace support operations are neither reliable nor predictable, especially in the context of high-tempo combat operations. While partners have demonstrated much flexibility and innovation, there is consensus that the current financing arrangements are unsustainable (AU, 2017b)

Post-conflict reconstruction and development (PCRD) and peace building are some of the most important challenges facing African countries emerging from conflicts. As the African Union continues to make progress in the prevention and resolution of conflicts, the imperative for comprehensive and integrated actions and plans for the recovery, reconstruction and development of societies recovering from conflicts becomes paramount(AU,2017b) 


\section{CONCLUSION}

Within state and interstate violent and additional intimidations to peace and security remain to challenge the African continent and will not hesitate last to fix so in this epoch. It has gotten indescribable sufferings to the continent as an entirely. Several security motivations have failed to return the anticipated effects. The continent mega politicians have derived to the practice that without Africa sets in place the suitable operative actions and ways to prevent, manage and alleviate encounters further extremely than ever before, the continent could remain to stand the terrible effects of conflicts. The AU framed the APSA with the African Stand by Force (ASF) at the midpoint of its peace and security program. Unluckily, the AU has found inadequate financial and logistics resources and the potential to carryout and achieves its peace and security initiatives. African influential politics have shortages in the political will and commitment and are not eager to pay attention to regional initiatives at the payment of their individual national programs. Funding, logistics requirements and capacity-building from Africa's development partners are indispensable to capacitate the AU's potential to achieve its peace and security program. African PSOs are mainly backed by the development partners and are significantly inclined by international advisers and expertise. Thus, the popular rhetoric of African solutions to African problems becomes a dilemma. However, Africa's development partners do not honor some of their financial initiates to funding African peace and security programs, thus making delays and hesitation. They focus more on giving that training support to the AU and its member states however, failing to deliver the badly needed logistics requirements

\section{REFERENCE}

[1] African Union. (2016a). Securing predictable and sustainable financing for peace and security in Africa. Addis Ababa

[2] African Union. (2016b). Assembly Decision: Assembly/AU/Dec.605 (XXVII) para 5b, of July 2016. Addis Ababa:

[3] African Union. (2017b). African Union Mission in Somalia (AMISOM) official website.

[4] AU, (2017a) annual report on the activities of the African union and its organs, Addis Ababa

[5] Bah,A. S;Choge-Nyangoro,E.;Dersso,S.;Mofya, B. nd Murithi,T.2014.The African Peace and Security Architecture, A Handbook.Friedrich Ebert Stiftung. 2014

[6] Bogland,Egnell and Lagerstrom,(2011)“The African Union, a Study Focusing on Conflict Management," 38-39.

[7] de Coning, C. (2014). Do we need a UN stabilization doctrine? In R. Gowan \& A. C. Smith (Eds.), what needs to change in UN peace operations? An expert briefing book prepared for the High-Level Independent Panel on Peace Operations (pp. 31-32). New York: New York University and International Peace Institute.

[8] Desmidt, S. (2016) Peace building, conflict prevention and conflict monitoring in the African Peace and Security

[9] European Commission (2013),African peace facility, Annual report ,Addis Ababa

[10] Fahle, F (2015) "The African Union mission in Somali; Toward a new vision of regional peace keeping" Peter.

[11] Gelot, L.,\& Karlsrud, J. (2016). The future of African peace operations: From Janjaweed to Boko Haram. London: Zed Books.

[12] Jamila EL Abdellaoui, "The Panel of the Wise, A Comprehensive Introduction to a Critical Pillar of the African Peace and Security Architecture," (ISS Paper 193, August 2009)

[13] Kristiana Powell, The African Union's Emerging Peace and Security Regime,Opportunities and Challenges on Delivering on the Responsibility to Protect (Ottawa: The North South Institute, 2005),3438. Theresa Whelan, "Why AFRICOM?" (Deputy Assistant Secretary of Defense for Africa, Department of Defense, August 2007),

[14] Lotze,W. (2013).Strengthening African peace support operations. Berlin: German Peace Operations Center (ZIF)

[15] Mark Malan, (2012),"Conflict Prevention in Africa: Theoretical Construct or Plan of Action?," 11.

[16] Murithi, T. (2007).The African Union's evolving role in peace operations: the African Union Mission in Burundi, the African Union Mission in Sudan and the African Union Mission in Somalia.African Security Review 17(1)

[17] Musah A (2011) "ECOWAS and Regional Responses to Conflicts" in Thomas Jaye, Dauda Garuba, Stella Amadi (eds.) ECOWAS and the Dynamics of Conflict and Peace- New Partnership for Africa's Development, NEPAD (2001) The New partnership for Africa'sdevelopment . 
[18] Paul D. Williams, (2009) "The Peace and Security Council of the African Union: Evaluating an Embryonic International Institution," in Journal of Modern African Studies, 47, 4 (Cambridge University Press:

[19] Tim Murithi and Angela Ndinga-Muvumba (Rapporteurs), "Building An African Union for the 21st Century, Relations with Regional Economic Communities, NEPAD and Civil Society,"(Policy Seminar Report, the Vineyard Hotel, Cape Town, 20-22 August 2005), 20. Franke,(205), Security Cooperation in Africa: A Reappraisal, 257.

[20] Tobias Debiel, (2009),“Conflict Early Warning and Response Mechanisms:Tools for Enhancing the Effectiveness of Regional Organizations? A Comparative Study of AU,Nathan Laurie, "Mediation and the African Union's Panel of the Wise," Crisis States Discussion Paper No 10, June 2005, 10,

[21] Wallensteen and Anders Bjurner (eds.) Regional Organizations and Peacemaking; Challengers to the UN Routeledge.

[22] Williams,P. D., \& Hashi, A.(2016). Exit strategy challenges for the African Union Mission in Somalia. Mogadishu: Heritage Institute for Policy Studies.

Citation: Yayew Genet Chekol. "Major Successes and Challenges of African Peace and Security Architecture (APSA)" International Journal of Political Science (IJPS), vol 5, no.2, 2019, pp. 1-8. doi:http://dx.doi.org/ 10.20431/2454-9452.0502001.

Copyright: (C) 2019 Authors. This is an open-access article distributed under the terms of the Creative Commons Attribution License, which permits unrestricted use, distribution, and reproduction in any medium, provided the original author and source are credited. 